\title{
Connections Between Ocean Bottom Topography and Earth's Climate
}

\author{
Steven R. Jayne \\ Woods Hole Oceanographic Institution - Woods Hole, Massachusetts USA
}

\author{
Louis C. St. Laurent \\ Florida State University • Tallahassee, Florida USA
}

\author{
Sarah T. Gille \\ Scripps Institution of Oceanography • La Jolla, California USA
}

The seafloor is one of the critical controls on the ocean's general circulation. Its influence comes through a variety of mechanisms including the contribution of mixing in the ocean's interior through the generation of internal waves created by currents flowing over rough topography. The influence of topographic roughness on the ocean's general circulation occurs through a series of connected processes. First, internal waves are generated by currents and tides flowing over topographic features in the presence of stratification. Some portion of these waves is sufficiently nonlinear that they immediately break creating locally enhanced vertical mixing. The majority of the internal waves radiate away from the source regions, and likely contribute to the background mixing observed in the ocean interior. The enhancement of vertical mixing over regions of rough topography has important implications for the abyssal stratification and circulation. These in turn have implications for the storage and transport of energy in the climate system, and ultimately the response of the climate system to natural and anthropogenic forcing. Finally, mixing of the stratified ocean leads to changes in sea level; these changes need to be considered when predicting future sea level.

\section{Topography and Ocean Mixing}

A review of the theory concerning the generation of internal waves over rough topography and their subsequent nonlinear interactions and mechanical mixing of the ocean is the subject of the paper by Kunze and Llewellyn Smith (this issue). Topographic steering and mixing associated with entrainment are discussed by Gille et al. (this issue). Here, we discuss the influence of tidal mixing on ocean circulation, and the Earth's climate.

Tides have long been considered to be decoupled from the ocean's general circulation. Indeed, tides were considered to be a solved problem in oceanography. The general physics of tides were understood, and they could be modeled with reasonable fidelity using relatively simple differential equations solved on computers. In general, it was thought that improvements in tide models would be made only by having higherresolution models run on faster computers. The advent of satellite altimetry by GEOSAT, more recently provided to a higher precision by TOPEX/Poseidon, reinvigorated interest in the tides. But the resulting research was largely an "engineering" issue related to perfecting the numerical models of the tides so that they could be used to remove tidal effects from the altimetry observations. However, in the process of refining tidal models, new and interesting physics were revealed. In particular, the application of data assimilation methods revealed that dissipation of the tides was more complicated than previously understood.

Egbert and Ray (2000) constrained their tide model with sea surface height data observed by the satellite altimeters. Using the residuals derived from the modeldata misfit, they were able to find regions where the model physics were incomplete. In particular, they found that their inverse model implied an enhanced dissipation in areas of the deep ocean. This dissipation could not be accounted for by the traditional bottom boundary layer physics. And while they could not use the residuals to determine definitively the mechanics of the missing dissipation, spatial maps of the dissipation were strongly suggestive. Most of the implied deep dissipation was concentrated along regions of rough bottom topography, such as mid-ocean ridges and island arcs, suggesting that these were regions where tidal energy was being converted to internal waves generated by the tides flowing over rough topography. The novel result of Egbert and Ray (2000) was that roughly 1 terawatt (TW) is dissipated in the deep ocean, which 


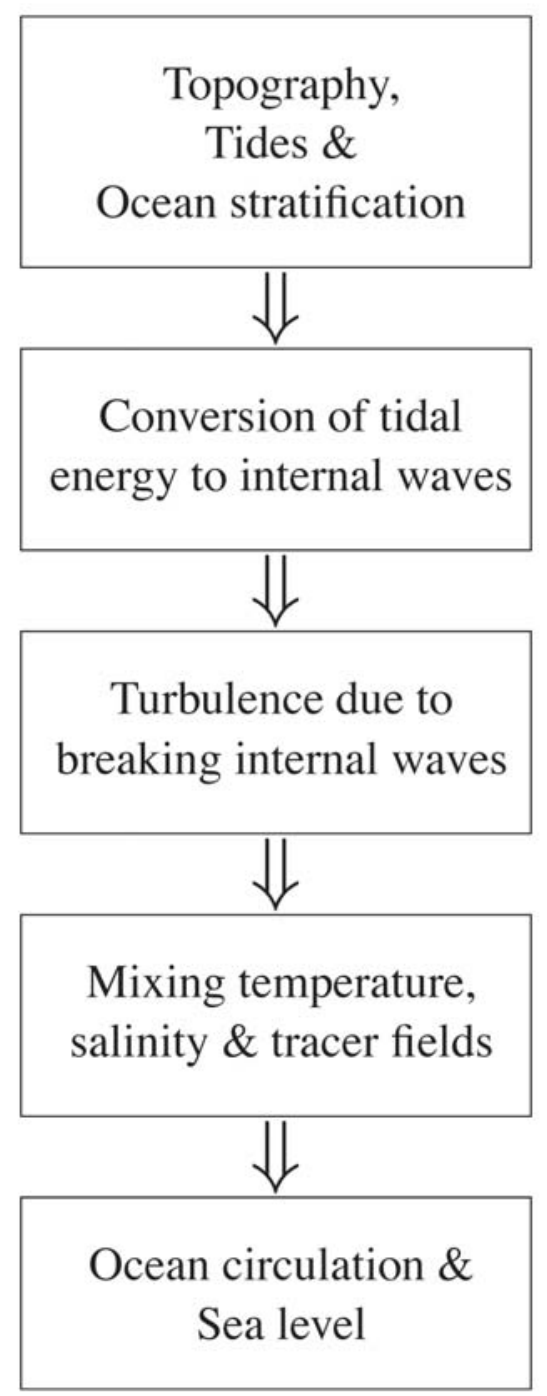

Figure 1. Ocean-bottom topography ultimately influences climate and sea level through a chain of effects. The tidal forces generated by the sun and moon cause tidal currents that flow over rough topography (in areas such as the mid-ocean ridges and seamounts) and in doing so move water vertically. These vertical motions, in the presence of stratification, create internal waves. Some of these internal waves propagate large distances from the topography that generated them and presumably contribute the general internal wave energy of the ocean. The waves that do not radiate away are unstable and breakup nonlinearly (similar to the way that surface waves breakup into white caps) near their location of generation. The breaking internal waves generate local patches of mechanical mixing of the ocean, which change the local temperature and salinity structure of the ocean. The changing ocean stratification in turn changes the largescale ocean currents (through geostrophy) and those in turn change the amount of heat the ocean transports. The changing ocean volume of the seawater even influences the overall sea level. is $25-30 \%$ of the total global tidal dissipation. This contrasts with the less than $1 \%$ of the tidal dissipation in the deep ocean that was traditionally estimated from scaling arguments (Munk, 1997).

This 1 TW of power is extracted from the ocean's tides through the generation of internal waves in the ocean's interior in regions of rough seafloor topography (Egbert and Ray, 2000; Jayne and St. Laurent, 2001). These waves represent the "internal tides," which ultimately dissipate their energy as turbulence throughout the global ocean. The mixing supported by dissipating internal tide energy influences the thermohaline structure of the deep ocean and provides buoyancy forcing for driving circulation in the abyss. Observations of greatly enhanced values of the vertical diffusivity were observed over rough topography in the Brazil Basin (Polzin et al., 1997; Ledwell et al., 2000). Vertical diffusivity is one of the key parameters controlling the ocean's general circulation, and in particular the strength of the overturning circulation (Bryan, 1987). A single value for the vertical diffusivity in the deep ocean is traditionally used in ocean general circulation models, though there have been studies that show a sensible circulation can be found even if all the mixing is confined to the boundaries (Marotzke, 1997).

An estimate of vertical diffusivity was inferred by Munk (1966), who found that the effective basin-wide diapycnal diffusivity in the deep waters of the North Pacific (and hence the global ocean) is approximately $1 \mathrm{~cm}^{2} / \mathrm{s}\left(1 \mathrm{~cm}^{2} / \mathrm{s}=10^{-4} \mathrm{~m}^{2} / \mathrm{s}\right)$. This has come to be regarded as the canonical value for mixing diffusivity throughout the ocean interior, despite its original context as an abyssal estimate. Recent observations using a deliberate tracer release in the thermocline by Ledwell et al. (1998) show the value of the vertical diffusivity in the thermocline waters is an order of magnitude lower than the canonical value, on the order of $0.1 \mathrm{~cm}^{2} / \mathrm{s}$. This mixing rate has been well documented in microstructure studies as characterizing thermocline regions throughout the ocean (Gregg, 1987), and $0.1 \mathrm{~cm}^{2} / \mathrm{s}$ is now regarded as the general background level of mixing for the ocean interior.

However, in the abyssal waters above the rough topography of the Mid-Atlantic Ridge, Ledwell et al. (2000) found that tracer dispersion and turbulent microstructure levels indicated that mixing rates were increased to values in the range of $2-4 \mathrm{~cm}^{2} / \mathrm{s}$ above the flank of the ridge and approximately $10-30 \mathrm{~cm}^{2} / \mathrm{s}$ nearer the bottom, two orders of magnitude above the background value. These observed enhanced mixing rates were attributed to breaking internal waves generated by tidal currents flowing over the rough topography found there. Further supporting this conclusion, they found that the microstructure-derived mixing rates were modulated by the local spring-neap cycle of the tides. St. Laurent and Garrett (2002) summarized other observational evidence of enhanced mixing rates associated with tidal flows over rough topography. 
Recent results from the Hawaii Ocean Mixing Experiment (Rudnick et al., 2003) have further established the connections among tides, internal waves, and enhanced mixing near topography.

These results represent a significant shift in our understanding of the ocean, and in particular, they imply that the tides are not decoupled from the rest of the ocean circulation. The tides are perhaps responsible for a large portion of the vertical mixing taking place in the ocean. In turn, the dissipation of tidal energy is affected by the stratification inherent in the ocean's general circulation.

Wunsch (1990) defined four key problems for oceanography to solve in what was then the next century, and is now the current century:

1. Mixing, including scale dependence, boundary enhancements, etc.

2. Air-sea transfer, heat flux, gas exchange, etc.

3. Where and how the ocean tides are dissipated.

4. Understanding the interactions in the ocean's internal wave field.

How surprising it is then that at the beginning of this century we find that three of these problems (namely 1, 3 and 4) turn out to be related and dependent on each other. If, as is likely the case, the tides and their enhanced dissipation over rough topography profoundly influence ocean mixing, then the fidelity of the current state-of-the-art ocean general circulation models that utilize uniform mixing in the deep ocean is strongly in doubt. This brings into question the ability of ocean models to represent the mixing of heat and the ocean circulation.

Figure 1 summarizes the steps connecting topography, the tides, ocean circulation and climate. Ultimately then, ocean mixing influences two properties of the ocean that directly affect humankind: Earth's climate and mean sea level. The Earth's climate is important in that it influences nearly every aspect of humanity from growing crops, energy usage, agricultural and municipal water supplies, to adverse weather such as droughts, floods and hurricanes. Changing sea level can lead to flooding and inundation of low lying areas, such as many of the major cities of the world to vast areas from Florida to Bangladesh. Therefore, investigations need to examine a complete picture of processes, from tidal flow, to the generation of the internal waves, to their breaking and mechanical mixing, to the influence of that mixing on the ocean circulation, and to its effects on climate and sea level. In our context, we ask: How does the tidally enhanced vertical mixing over rough topography impact the ocean circulation, its heat transport and our understanding of the ocean's role in climate dynamics? How does mixing affect our ability to predict future sea level change? We address each of these in the following sections.

\section{Impacts of Mixing on Ocean Circulation}

Direct observational evidence on the connection among tidal dissipation, mixing, and the large-scale ocean circulation is not available. Therefore our insights rely largely on the results from numerical models of the ocean circulation. Presently popular schemes in ocean general circulation models for parameterizing mixing use fixed values of diapycnal diffusivity. These are usually assigned $a d$ hoc, as a means of tuning the model's meridional transports of heat and mass. While this practice results in aligning modeled properties with the presently observed state of the ocean, the parameterized rate of mixing has no ability to evolve with a changing ocean. This is problematic, as understanding and predicting changes in the state of the ocean, and hence the climate system, is a primary goal of most modeling efforts. Ocean modeling studies have shown that oceanic heat transports are extremely sensitive to variations in the diffusivity (Bryan, 1987; Marotzke, 1997). Variations in diffusivity have also been shown to have a large impact on the modeled uptake and storage of climatically important tracers such as carbon (Sokolov et al., 1998).

Since ocean mixing is an important parameter controlling ocean circulation, it is worthwhile to consider what ocean models should strive for to correctly represent the mixing. It has been observed that the magnitude of ocean mixing has a wide range of variation throughout the ocean. The observed turbulent diffusivities in the ocean interior range from $0.1 \mathrm{~cm}^{2} / \mathrm{s}$ in the thermocline (Ledwell et al., 1998) to greater than 10 $\mathrm{cm}^{2} / \mathrm{s}$ in the deep ocean above regions of rough topography (Polzin et al., 1997; Ledwell et al., 2000). To sustain these turbulent diffusivities, and the resultant increase in the ocean's potential energy, there must be a constant supply of mechanical energy. The main source of this energy is the internal wave field of the ocean. Some internal wave energy is derived from the transmission of wind energy through the surface mixed layer (Alford, 2001). Tidal flow over rough seafloor topography acts as the other main source of internal waves in the deep ocean, and rough topography is ubiquitous throughout the global ocean (Figure 2).

One method of quantifying mixing in the ocean is through large-scale balances of mass, heat, and salt. Based on an assumed estimate of the upwelling, Munk (1966) inferred that Pacific intermediate and abyssal waters (i.e., water between 1000 and $4000 \mathrm{~m}$ ) mix with an average diffusivity of $1 \mathrm{~cm}^{2} / \mathrm{s}$. Abyssal water mass 


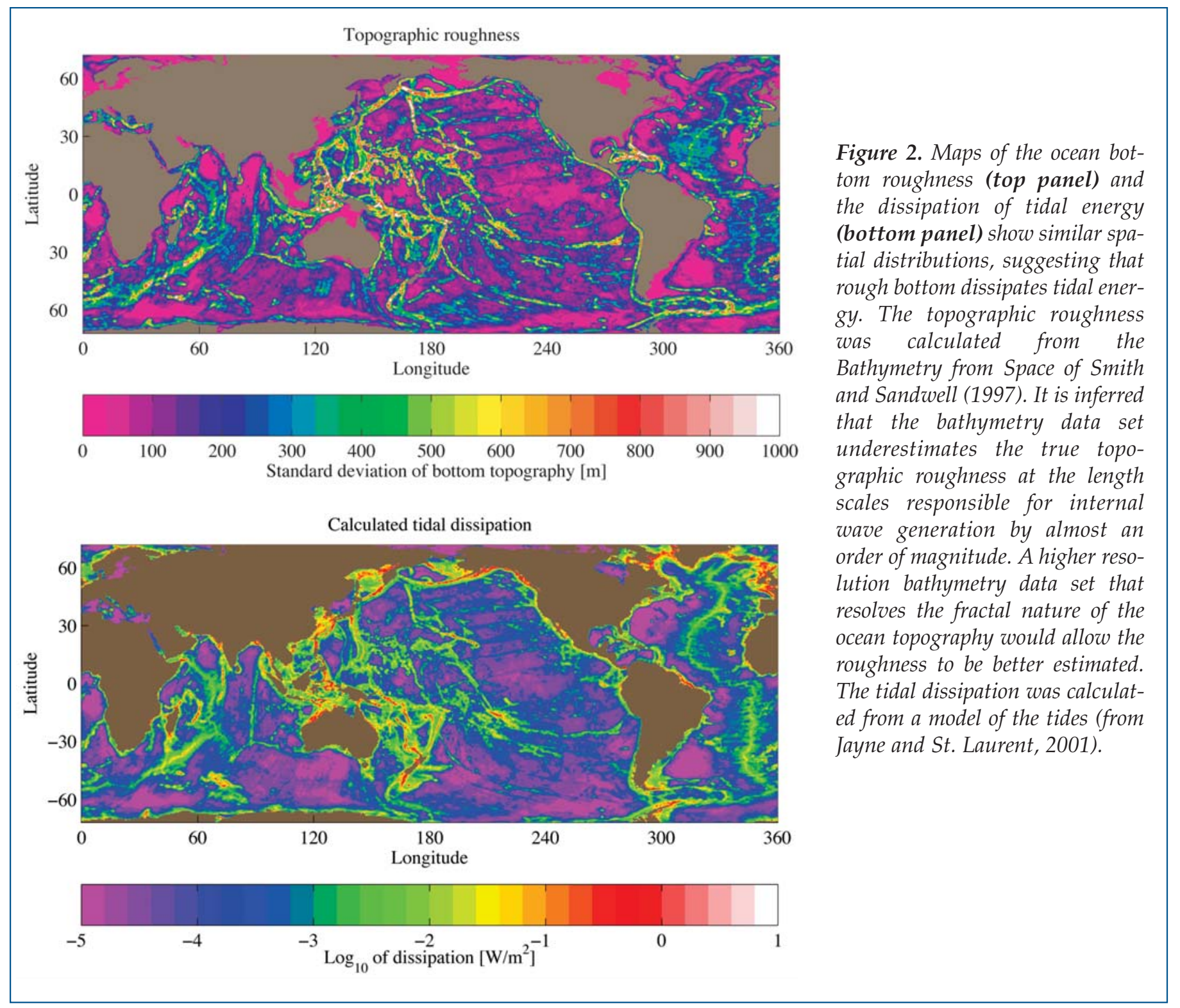

conversions in the Brazil Basin have been studied using hydrography, current meter measurements, and control volume methods (Morris et al., 2001). These studies suggest that diffusivities of the order $1 \mathrm{~cm}^{2} / \mathrm{s}$ influence the basin-averaged budgets of heat and mass, and deep diffusivity estimates in excess of order $1 \mathrm{~cm}^{2} / \mathrm{s}$ have been derived for many semi-enclosed basins. Direct measurements of mixing in the upper ocean and thermocline (but below the mixed layer) consistently reveal smaller diffusivities near $0.1 \mathrm{~cm}^{2} / \mathrm{s}$. Similar values are observed throughout the full ocean depth over smooth abyssal plains and appear to represent a background level of turbulence supported by the internal wave continuum (Munk, 1981). Above rough topography in the Brazil Basin (Figure 3), mixing rates were observed to be orders of magnitude above background levels (Polzin et al., 1997; Ledwell et al., 2000). In these locations, elevated diffusivities extend hundreds of meters above the ocean floor.
Another perspective on mixing comes from the consideration of global energy balances. To maintain the observed density stratification against an assumed overturning rate, Munk and Wunsch (1998) calculated that 2 TW must be dissipated throughout the ocean. Independent analyses of the tides using analytical methods, altimetry, and tidal modeling reveals that approximately $1 \mathrm{TW}$ of the total $3.5 \mathrm{TW}$ of tidal energy dissipation is lost from the barotropic tides through the generation of internal tides in the deep ocean, predominantly around regions of rough topography such as mid-ocean ridges (Egbert and Ray, 2000; Jayne and St. Laurent, 2001). This energy must ultimately be dissipated, presumably supporting diapycnal mixing. Additional energy required to maintain the inferred mixing is thought to be provided by the wind work on the mixed layer and the ocean general circulation (Munk and Wunsch, 1998; Wunsch, 1998; Alford, 2001). 


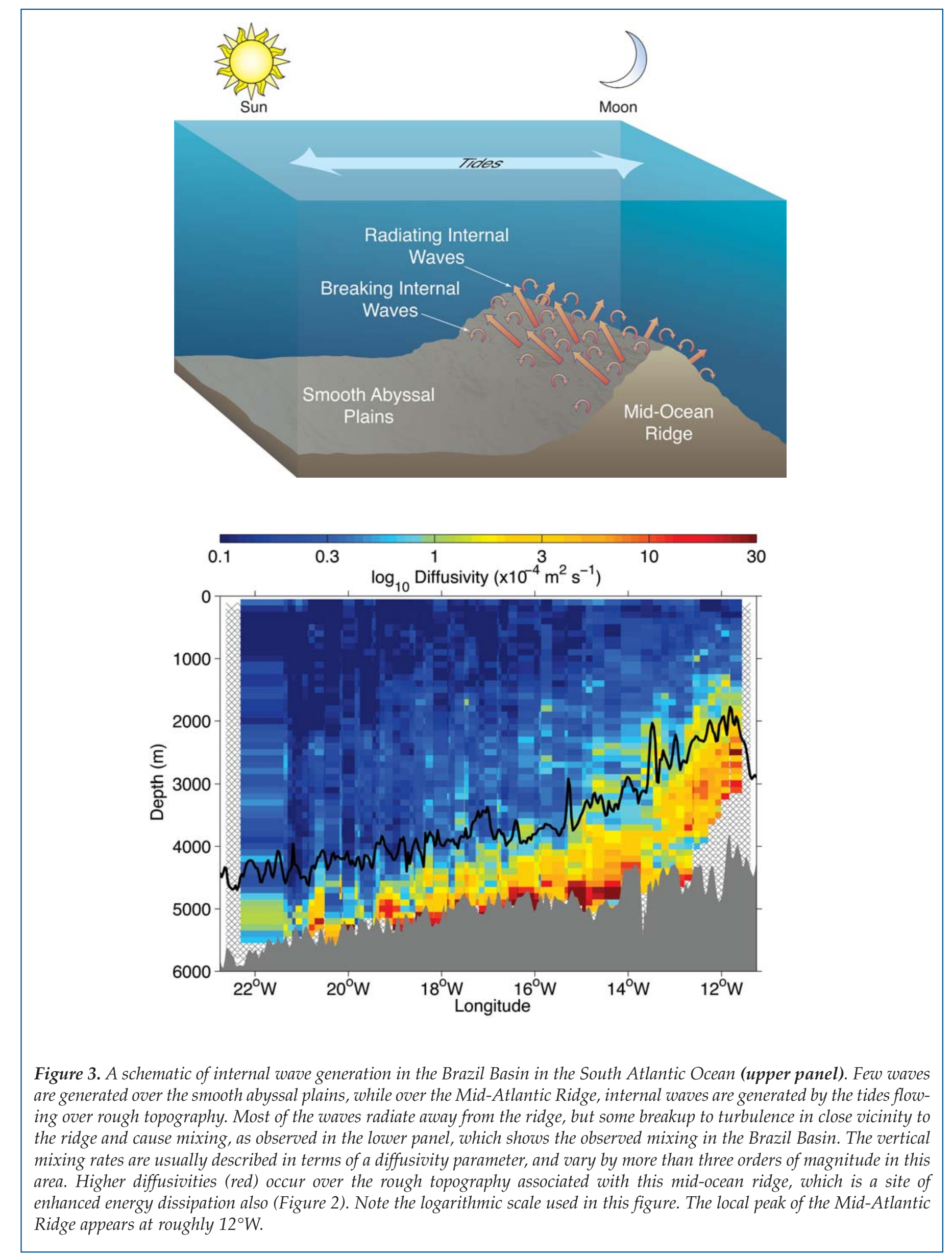



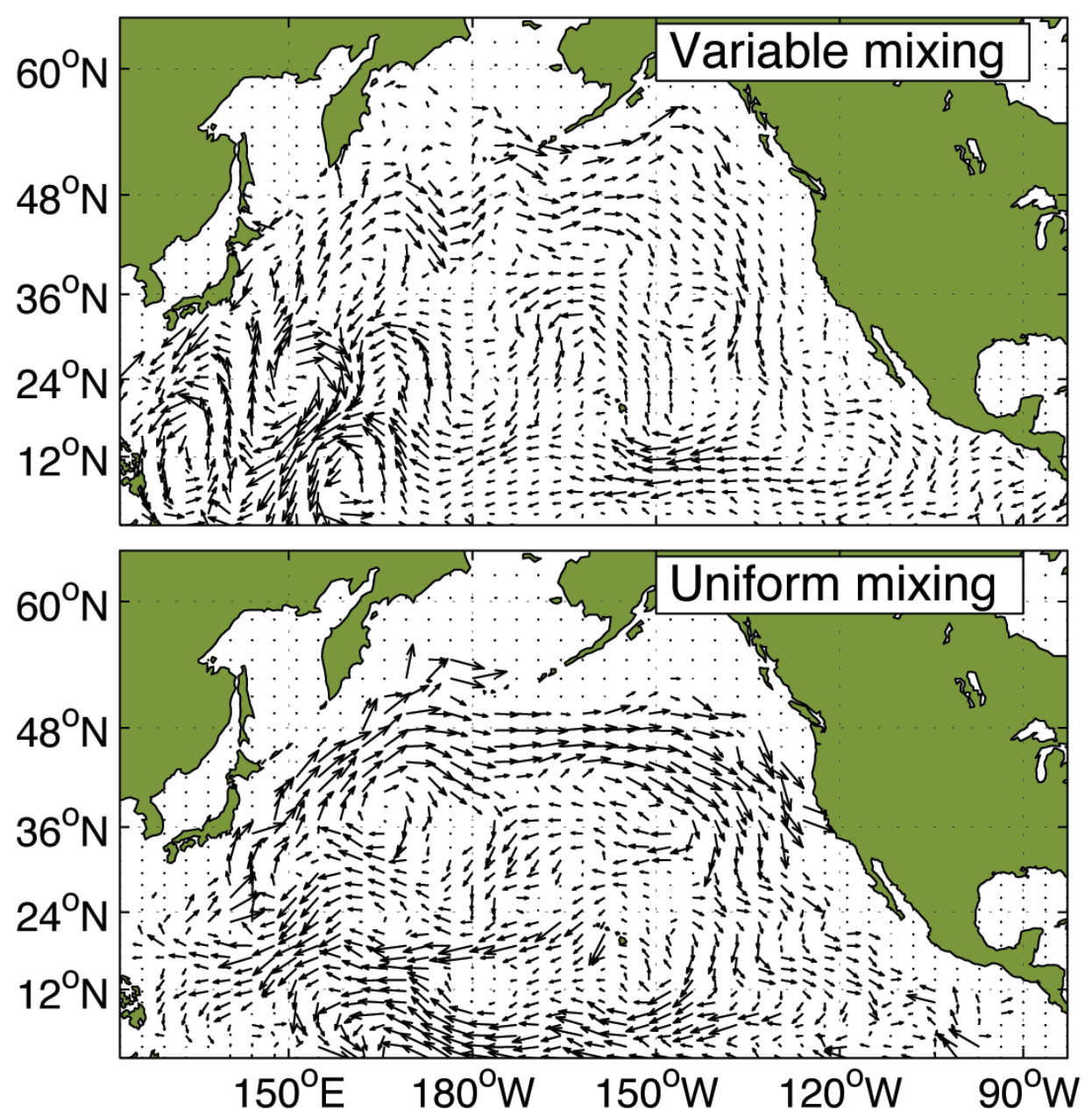

Figure 4. Computer simulations of ocean circulation are very sensitive to how ocean mixing is modeled. Traditionally, computer models of the ocean have made the simplifying assumption of globally uniform mixing. This figure shows the vertically averaged deep flow in the North Pacific from a numerical model. In one version of the model, the mixing was set to be constant (lower panel), in the second version of the model, it was set according to a parameterization of spatially varying tidal mixing (upper panel). Examining the modeled flow, there are dramatic differences between the spatially variable and uniform mixing experiments. The flow in the variable mixing case is much more spatially inhomogeneous and convoluted. The consequences for the climatically important heat transport are shown in the next figure (from Simmons et al., 2004).

The prediction of the Earth's climate has been an important area of research for the last half century. While incredible progress has been made in understanding the factors that control the climate, there are still significant gaps in our understanding. These unanswered questions about the climate cast aspersion on the ability of climate models to forecast future climate change with the anthropogenic changes that are now underway (IPCC, 2001). In that the ocean is an important component of the climate system, and mixing is an important control on the ocean, mixing processes must be correctly modeled to allow accurate prediction of the changing climate.

As an indication of how sensitive the simulated ocean circulation and heat transport are to the specified mixing, Simmons et al. (2004) compared two model simulations in which ocean mixing was varied. In one version of the ocean model, mixing was set everywhere to be a constant value; in the other version of the model, mixing was varied spatially according to a parameterization of the mixing expected from breaking internal waves. Figure 4 shows the deep-ocean circulation calculated in the two different models. The model version that had the spatially varying mixing has a much richer and variable circulation field than the version with a spatially uniform mixing. This indicates that the model's circulation is sensitive to the specification of the vertical mixing. Therefore, to understand and correctly simulate the ocean's circulation, it is necessary to know what controls ocean mixing and how it relates to the ocean's topography.

The ocean's circulation field transports heat, and 
the equator-to-pole heat transport is a critical component of the Earth's climate system. One example of the role of the ocean's heat transport has in modulating climate is that of the Atlantic Ocean carrying warm water towards Europe, making winters there milder than those at the comparable latitudes of North America. In the same set of model experiments by Simmons et al. (2004), ocean heat transport was also calculated, and is shown in Figure 5. It shows that the estimated ocean heat transport is also sensitive to the specified mixing.

To summarize, the stratification of the ocean is intimately related to the large-scale circulation of the ocean and its resultant heat transport. Understanding the dynamics that maintain the structure of the deep ocean's stratification, of which mixing is a primary factor, is of fundamental importance to understanding large-scale ocean circulation.

Finally, there is a more speculative way in which the tides may influence climate. The tides have been implicated in observed climate variability over a range of periods from the spring-neap cycle, the 18.6-year nodal cycle, and millennial time scales. Climate cycles such as Milankovitch orbital periods, the El NiñoSouthern Oscillation, and the North Atlantic Oscillation have been some of the most researched topics in climate science, and the QuasiBiennial Oscillation is well known in the atmospheric literature. Perhaps it is because of the inherent predictability that cycles offer to long-range forecasts that they have garnered so much interest. Nonlinear interactions among various tidal constituents lead to a few welldefined periodicities in the tidal forcing, and presumably dissipation and hence vertical mixing (Keeling and Whorf, 1997). The tides, particularly the 18.6year nodal cycle, have been implicated as a key forcing mechanism in a diverse host of climate phenomena, including surface air temperatures, droughts, and even modulating the strength of El Niño. However, to date, no plausible mechanism has been demonstrated to explain these relationships to the tides, and there is reason to be skeptical that the long-period (millennial time

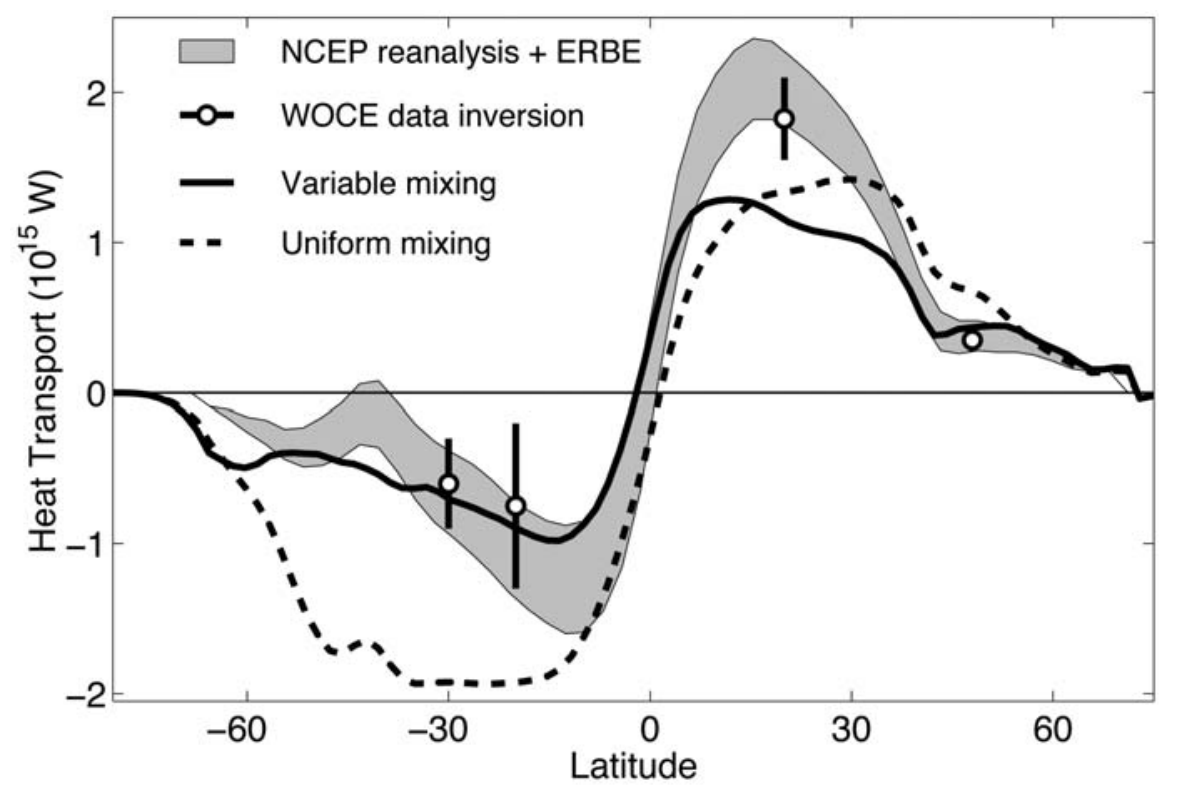

Figure 5. The transport of heat from the equator to the poles is a critical component of the Earth's climate system, and must be modeled correctly to accurately predict global change. Whether or not an ocean model accounts for non-uniform mixing will change that model's predictions of the poleward heat transport. As in Figure 4, models with (solid line) and without (dashed line) variable mixing are compared. The model including variable mixing does a much better job of matching the poleward heat flux seen in the numerical weather prediction model reanalysis from the National Center for Environmental Prediction (NCEP) constrained by the Earth Radiation Balance Experiment (ERBE) satellite observations, and the heat flux inferred from World Ocean Circulation Experiment (WOCE) data (Simmons et al., 2004). 


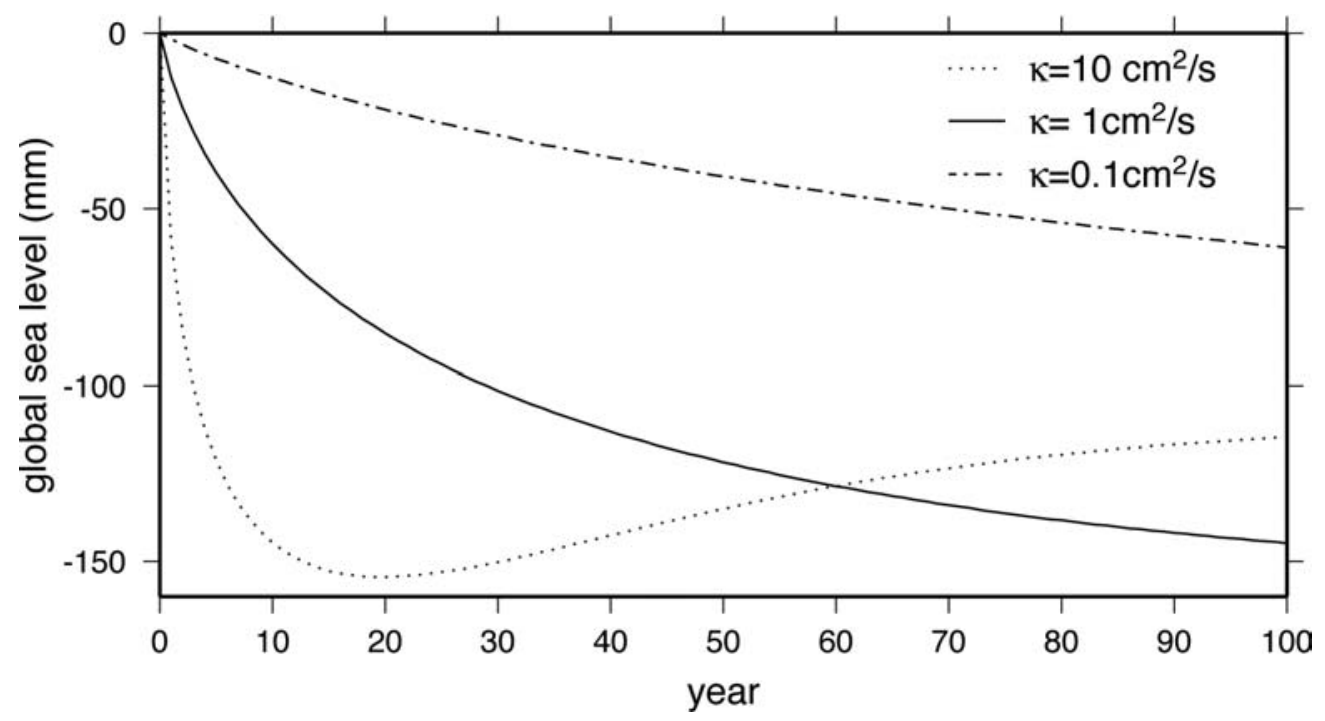

Figure 6. Global sea level appears to be rising. To interpret sea level rise one must consider that, in the absence of other factors, mixing ocean water would cause sea level to fall. This is due to the peculiarities of the equation of state that governs how much volume a mass of water will occupy. The rate of sea level fall due to mixing depends on the mixing rate. Since mixing rates in the ocean are quite variable (Figure 3) the impact of mixing must be included in order to make sense of observed sea level rise. Shown here are model predictions of globally averaged sea level resulting from vertically mixing the ocean with diffusion coefficients ranging from $\kappa=0.1 \mathrm{~cm}^{2} / \mathrm{s}$ (dash-dotted line) to $\mathrm{\kappa}=10 \mathrm{~cm}^{2} / \mathrm{s}$ (dotted line). The curves are self-similar: 10 years of diffusion with $\mathrm{\kappa}=10 \mathrm{~cm}^{2} / \mathrm{s}$ are equivalent to 100 years of diffusion with $\mathrm{\kappa}=1 \mathrm{~cm}^{2} / \mathrm{s}$. For long time periods, sea-level drop asymptotes to $109 \mathrm{~mm}$ (from Gille, 2004).

scales) tidal variations are significant enough to be important (Munk et al., 2002). Changes in the tidal forcing on decadal time scales may lead to a modulation of vertical mixing and in turn ocean circulation, ocean heat transport and/or the sea surface temperature (Loder and Garrett, 1978). These variations in ocean state may then modify global climate by altering surface boundary conditions and fluxes seen by the atmosphere. If tidal cycles do assert themselves as transient climate variations, then they potentially offer a strong predictive tool.

To know the response of the ocean circulation to changes in its forcing, it is necessary to fully understand the dynamics that dictate the present-day ocean circulation, and how those controls would change in the future. It has been shown that ocean mixing, and in particular its enhancement near rough topography, is a primary factor in determining the ocean's circulation. Understanding the dynamics that control today's climate provides us with the keys to unlock the climate of the past and opens the door to predicting the climate of the future. Predictions based on climate models rely on their ocean component model to correctly transport and mix heat in the climate system; their lack of appropriate physics degrades the fidelity of those predictions.

Impacts of Mixing on Sea Level

Mixing also has a direct impact on sea level, since it determines how heat, salinity, and fresh water are transported and stored in the ocean. An important part of sea-level change is that arising from the changing ocean heat storage, since warm water occupies a larger volume than cooler water. Predictions of global sea-level rise over the next century differ by $25 \%$ or more depending on the rate of vertical mixing. The fundamental processes are nonlinear. Variations in mixing induce variations in density-dependent (steric) sea level. Global sea-level rise has been widely recognized as a potentially significant consequence of global climate change. The ability to measure, predict, and characterize the rate of sea-level rise is one of the major objectives of current climate research. During the 20th century, the observed sea-level rise was $1.84 \pm 0.35 \mathrm{~mm} /$ year (Douglas, 2001). Although much of this can be ascribed to known sources, such as thermal expansion of the oceans and melting ice sheets and alpine glaciers (Church et al., 2001), some large fraction is still unaccounted for.

Forecasts of long-term sea level rise depend on numerical climate models. One challenge in developing these models is to establish realistic values of horizontal and vertical diffusion coefficients. Diffusion rates typically parameterize a broad range of unresolved subgrid-scale motions that are not well understood. To maintain computational stability, numerical 
climate models often use diffusivities that exceed estimated realistic values. As a result, temperature and salinity gradients in climate models can diffuse away over time. These results suggest that this long-term diffusion process will also slowly form denser water and decrease global sea level. Diffusion rates also strongly influence the rate at which heat penetrates the deep ocean, because high diffusion transfers heat more rapidly from the atmosphere to the ocean. For example, Sokolov et al. (1998) have shown that sea-level rise in a simplified climate model is sensitive to vertical diffusion rates.

One possible contributor to sea-level change is the direct impact of ocean mixing. The process of mixing water masses that have differing temperatures, salinities, and pressures creates water that is typically denser than the original water. Thus mixing the ocean, either along isopycnals or vertically, tends to decrease global sea level, even when no heat or salt is added to the ocean. Gille (2004) tested the sensitivity of sea level to diffusivity with a simple model. Using data from the World Ocean Atlas 1998 (Levitus et al., 1998), potential temperature and salt were vertically diffused over the top $3000 \mathrm{~m}$ of the water column. After a simulation of 10 years, results showed that a relatively small diffusion coefficient of $0.1 \mathrm{~cm}^{2} / \mathrm{s}$ led to a sea-level change of $12 \mathrm{~mm}$. In contrast, if the diffusion coefficient was $1 \mathrm{~cm}^{2} / \mathrm{s}$ then in 10 years, sea level changed by $57 \mathrm{~mm}$ (Figure 6). Regionally the effects were even larger. These diffusion coefficients are typical of pelagic conditions and the estimated global average, respectively (Munk and Wunsch, 1998). The rudimentary calculation looks at the effect of changing only one of the controls on the ocean, and neglects spatial variability of mixing. The result clearly suggests that improving our knowledge of vertical mixing will help refine sea level estimates. Improved mixing models based on improved bathymetry data sets will permit further quantification of the effect of mixing on regional and global sea-level change.

\section{Summary}

We have outlined the connections among ocean bathymetry, tides, ocean circulation and heat transport, sea level and more generally the Earth's climate. While these areas are the subject of continuing research and debate, the basic physics appear to be identified. The ocean tides flowing over rough topography create internal waves, some of which break up into turbulence, causing ocean mixing. This mixing determines the stratification of the ocean and influences the ocean's circulation and heat transport, as well as the penetration of heat and gases from the atmosphere into the deep ocean. Numerical models of ocean circulation are sensitive to the details of the specified ocean mixing, and so mixing must be correctly parameterized in order for the models to correctly simulate the ocean. Ocean models are key components of climate system models, and the fidelity of these models depends critically on simulating each part of the climate system correctly. Therefore ocean models must include all the important physics to properly represent the real ocean's dynamics.

Ocean mixing has been shown to be a critical control on the ocean's circulation, and since ocean mixing depends strongly on ocean topography, we conclude that the ocean's bathymetry needs to be known in detail over the entire globe. While existing topographic data sets are capable of defining the gross details of rough topography, they cannot fully resolve all the length scales responsible for internal wave generation, and clearly underestimate the true topographic roughness at the length scales responsible for internal wave generation by almost an order of magnitude. A higherresolution bathymetry data set will improve our ability to better quantify ocean mixing, and understand its impact on the Earth's climate. [es

\section{Acknowledgments}

We would like to thank all the participants in the Global Bathymetry for Oceanography, Geophysics, and Climatology Workshop, and in particular, Eric Kunze, Stefan Llewellyn Smith, and Harper Simmons for providing material and helpful suggestions. SRJ was supported by the National Science Foundation under grant OCE-0241061 and an Office of Naval Research Young Investigator Award, LCS was supported by the Office of Naval Research under grant N00014-03-1-0307, and STG was supported by the National Science Foundation under grant OCE9985203/OCE-0049066 and by the National Aeronautics and Space Administration under JPL contract 1224031.

\section{References}

Alford, M.H., 2001: Internal swell generation: The spatial distribution of energy flux from the wind to mixed layer near-inertial motions. J. Phys. Oceanogr., 31, 2359-2368.

Bryan, F., 1987: Parameter sensitivity of primitive equation ocean general circulation models. J. Phys. Oceanogr., 17, 970-985.

Church, J., et al., 2001: Chapter 11, Change in sea level. In: Intergovernmental Panel Climate Committee (IPCC) Working Group 1 (WG1) Third Assessment Report.

Douglas, B., 2001: Sea level change in the era of the recording tide gauge. Chapter 3. in: Sea Level Rise: History and Consequences, B.C. Douglas, M..S. Kearney, and S.P. Leatherman, eds., Academic Press.

Egbert, G.B., and R.D. Ray, 2000: Significant dissipation of tidal energy in the deep ocean inferred from satellite altimeter data. Nature, 405, 775-778.

Gille, S.T., 2004: How non-linearities in the equation of state of sea water can confound estimates of steric 
sea level change. J. Geophys. Res., in press.

Gregg, M.C., 1987: Diapycnal mixing in the thermocline: A review. J. Geophys. Res., 92, 5249-5286.

IPCC, 2001: Climate Change 2001: The Scientific Basis. Contribution of Working Group I to the Third Assessment Report of the Intergovernmental Panel on Climate Change. Houghton, J.T., et al., eds., Cambridge University Press, Cambridge, United Kingdom, 881pp.

Jayne, S.R., and L.C. St. Laurent, 2001: Parameterizing tidal dissipation over rough topography. Geophys. Res. Lett., 28, 811-814.

Keeling, C.D., and T.P. Whorf, 1997: Possible forcing of global temperature by the oceanic tides. Proceedings of the National Academy of Sciences, 94, 8321-8328.

Ledwell, J.R., A.J. Watson, C.S. Law, 1998: Mixing of a tracer released in the pycnocline. J. Geophys. Res., 103, 21,499-21,529.

Ledwell, J.R., E.T. Montgomery, K.L. Polzin, L.C. St. Laurent, R.W. Schmitt, and J.M. Toole, 2000: Evidence for enhanced mixing over rough topography in the abyssal ocean. Nature, 403, 179-182.

Levitus, S., T.P. Boyer, M.E. Conkright, T. O’Brien, J. Antonov, C. Stephens, L. Stathoplos, D. Johnson, and R. Gelfeld, 1998: World ocean database 1998, volume 1: Introduction, NOAA Technical Report, Atlas NESDIS 18, 346 pp.

Loder, J.W., and C. Garrett, 1978: The 18.6-year cycle of sea surface temperature in shallow seas due to variations in tidal mixing. J. Geophys. Res., 83, 19671970.

Marotzke, J., 1997: Boundary mixing and the dynamics of three-dimensional thermohaline circulation. J. Phys. Oceanogr., 27, 1713-1728.

Morris, M., M.H. Hall, L.C. St. Laurent, and N.G. Hogg, 2001: Abyssal mixing in the Brazil Basin. J. Phys. Oceanogr., 31, 3331-3348.

Munk, W., 1966: Abyssal recipes. Deep-Sea Res., 13, 707730.

Munk, W., 1981: Internal waves and small-scale processes. Pp. 264-291 in Evolution of Physical Oceanography Scientific Surveys in Honor of Henry Stommel, B.A. Warren, and C. Wunsch, eds., MIT Press, Cambridge, Massachusetts.

Munk, W., 1997: Once again: once again-tidal friction. Prog. Oceanogr., 40, 7-35.

Munk, W., and C. Wunsch, 1998: Abyssal recipes II: Energetics of tidal and wind mixing. Deep-Sea Res., 45, 1977-2010.

Munk, W., M. Dzieciuch, and S.R. Jayne, 2002: Millennial climate variability; Is there a tidal connection? J. Clim., 15, 370-385.

Polzin, K.L., J.M. Toole, J.R. Ledwell, and R.W. Schmitt, 1997: Spatial variability of turbulent mixing in the abyssal ocean. Science, 276, 93-96.

Rudnick, D.L., et al., 2003: From tides to mixing along the Hawaiian ridge. Science, 301, 355-357.

St. Laurent, L.C., H.L. Simmons, and S.R. Jayne, 2002:
Estimates of tidally driven enhanced mixing in the deep ocean. Geophys. Res. Lett., 29, doi:10.1029/ 2002 GL015633.

St. Laurent, L.C., and C. Garrett, 2002: The role of internal tides in mixing the deep ocean. J. Phys. Oceanogr., 32, 2882-2899.

Simmons, H.L., S.R. Jayne, L.C. St. Laurent, and A.J. Weaver, 2004: Tidally driven mixing in a numerical model of the ocean general circulation. Ocean Modelling, 6, 45-263.

Smith, W.H.F., and D.T. Sandwell, 1997: Global sea floor topography from satellite altimetry and ship depth soundings. Science, 277, 1956-1962.

Sokolov, A., C. Wang, G. Holian, P. Stone, and R. Prinn, 1998: Uncertainty in the ocean heat and carbon uptake and its impact on climate projections. Geophys. Res. Lett., 25, 3603-3606.

Wunsch, C., 1990: Comments on R.W. Stewart's "Physical Oceanography to the End of the Twentieth Century", In: Quo Vadimus: Geophysics for the Next Century, G. D. Garland and J.R. Apel, eds.

Wunsch, C., 1998: The work done by the wind on the ocean circulation. J. Phys. Oceanogr., 28, 2332-2340.

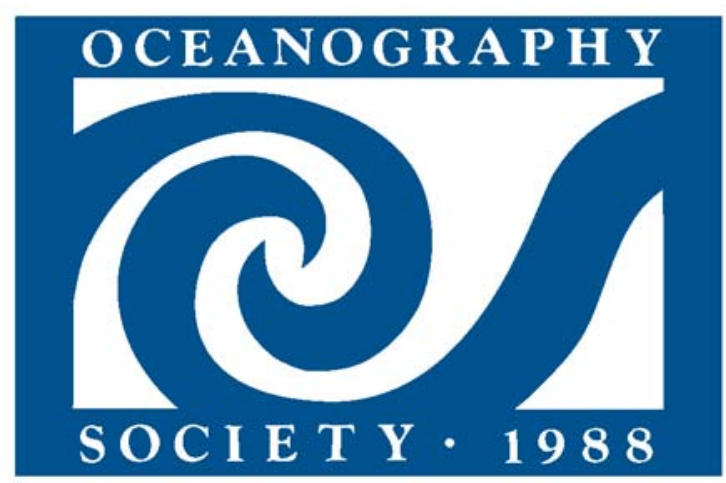

